\title{
THE RESPONSE OF ARRHYTHMIAS AND TACHYCARDIAS OF SUPRAVENTRICULAR ORIGIN TO ORAL PROCAINE AMIDE
}

\author{
BY \\ JEROME A. SCHACK, IRWIN HOFFMAN, AND HARRY VESELL \\ From the Medical Service and Cardiographic Laboratory, Beth Israel Hospital, New York
}

Received January 14, 1952

The introduction of procaine amide for the control of cardiac arrhythmias in man has been recent (Mark et al., 1950). There are relatively few reports at present concerned with it. Those published have dealt chiefly with the use of the preparations of the drug given by intravenous injection and have emphasized its value in arrhythmias of ventricular origin (Mark et al., 1950; Joseph et al., 1951; Garlett et al., 1951; Kinsman et al., 1951; Miller et al., 1951; Kayden et al., 1951; and Stearns and Callahan, 1951). Thus, it has been stated that procaine amide is of value in ventricular arrhythmias but that its effect " on auricular function appears to be minimal " (Joseph et al., 1951).

With the advent of the preparation for use by mouth,* a study of the action of orally administered procaine amide upon supraventricular disturbances of the heart beat was undertaken.

\section{MATERIAL AND METHODS}

This report is based upon observations of 100 instances of supraventricular arrhythmias or tachycardias which occurred in 83 patients in the Beth Israel Hospital during the past year and a half, admitted because of organic heart disease. None were patients under anæsthesia for surgery. All were between 25 and 75 years of age, the majority being between 40 and 60 years. The sex distribution was approximately equal.

The drug, procaine amide, was given by mouth, and according to the following schedule.

A test dose of $250 \mathrm{mg}$. was followed in one hour by a $1-\mathrm{g}$. oral dose. Thereafter, $1 \mathrm{~g}$. every four hours was administered. If, after $5 \mathrm{~g}$. of the drug had been given, the arrhythmia had not been abolished, the drug schedule was changed to $1 \mathrm{~g}$. every three hours.

In all cases the drug was continued until the arrhythmia was abolished or some toxic effect occurred. Following the restoration to sinus rhythm, the dosage was gradually reduced over the course of the succeeding forty-eight hours to $0.5 \mathrm{~g}$. every six hours.

In those subjects in whom the arrhythmia could not be abolished with procaine amide, a course of oral quinidine sulphate, $0.4 \mathrm{~g}$. every two hours was undertaken. The quinidine was also given until the arrhythmia was converted or toxic effects produced.

In several instances following restoration of sinus rhythm by means of procaine amide, the drug was withdrawn, the arrhythmia allowed to recur and procaine amide again administered with restoration of sinus rhythm.

* Supplied as pronestyl hydrochloride by E. R. Squibb \& Co. 


\section{RESULTS}

Many supraventricular arrhythmias responded to procaine amide. In these patients, neither the type of heart disease nor the presence of digitalis medication influenced the action of procaine amide significantly. The most important factors were the type and duration of the arrhythmia.

Auricular Fibrillation. The cases of auricular fibrillation have been considered in three groups: (A) those subjects in whom the auricular fibrillation was of less than one week's duration; (B) those in whom the auricular fibrillation was of longer than one week's duration but clearly less than three years; and (C) those in whom auricular fibrillation had been present for three years or longer.

Group $A$. There were 21 patients with auricular fibrillation of less than one week's duration. Restoration of sinus rhythm with procaine amide occurred in 17. Conversion occurred in two instances after only $1.25 \mathrm{~g}$. of the drug had been taken. In most instances, however, it required 3 to $4 \mathrm{~g}$. for conversion. In the four instances of failure to correct the arrhythmia, quinidine also failed to secure reversion to normal sinus rhythm. No significant toxicity to the drug was observed in this group.

Group B. There were 25 patients whose fibrillation was of longer than one week but less than three years duration. Fifteen were restored to regular sinus rhythm by means of procaine amide. In three, the auricular fibrillation was converted to auricular flutter but restoration to sinus rhythm could not be accomplished. For conversion in this group, 3 to $6 \mathrm{~g}$. of the drug were usually required. There were several instances of rather severe toxicity, but the effects did not last more than 36 hours. Much nausea, diaphoresis, and prostration occurred in two subjects. Hypotension was not observed. In one patient (J. G.) whose cardiogram revealed " unstable bundle branch block" dependent upon a critical ventricular rate, the ventricular rate became rapid, about 170, after procaine amide and the cardiogram then resembled ventricular tachycardia (Vesell and Kraemer, 1951; Langendorf, 1948; and Kay, 1948). At that time the patient experienced severe malaise and weakness. There was one instance in which, following the establishment of regular sinus rhythm, a cerebral embolism occurred. Sinus rhythm was restored with quinidine in only one of the patients in whom the arrhythmia could not be abolished with procaine amide. In a second fibrillation was converted to flutter but sinus rhythm could not be established.

Group $C$. There were 15 patients in whom auricular fibrillation had been known to be present for three years or longer. Only three could be restored to regular sinus rhythm by use of procaine amide. Each of the three patients in whom restoration of sinus rhythm took place received $5 \mathrm{~g}$. of the drug within 20 hours. Seven of those who did not respond to procaine amide were given quinidine sulphate by mouth: $0.4 \mathrm{~g}$. every two hours. In none of these was restoration of sinus rhythm accomplished. In this group of patients there were two instances of untoward reactions in the form of severe gastro-intestinal symptoms; nausea, epigastric distress and a sensation of fullness in the throat.

Auricular Flutter. Regular sinus rhythm was restored in only one of seven instances of auricular flutter by means of procaine amide. In this patient, when the drug was withdrawn, auricular flutter recurred and sinus rhythm was again restored with procaine amide. The presence of auricular flutter had been recognized for six months and previous attempts at conversion with quinidine sulphate orally had failed. The flutter proved remarkably sensitive to procaine amide, responding to doses of $0.5 \mathrm{~g}$. every four hours, conversion occurring when only $1.5 \mathrm{~g}$. of the drug had been taken. Five of the other patients with auricular flutter were quite resistant to procaine amide. One received $12 \mathrm{~g}$. of the drug within 36 hours. Two of these patients showed severe systemic and gastro-intestinal reactions to the drug. One patient, with multiple pulmonary emboli, expired suddenly while under therapy; it was believed that death was due to a pulmonary embolus and not to the drug.

Quinidine sulphate was without effect in two subjects, but converted the flutter to auricular 
fibrillation in one other. An effect similar to that which has been observed with quinidine was noted in one patient with auricular flutter after he had received $1 \mathrm{~g}$. of procaine amide; as the flutter rate was slowed from 216 to 188 a one-to-one ventricular response took place. Ventricular complexes at the rapid rate were of the previous supraventricular type. However, over the course of the succeeding hour, they gradually widened to $0.16 \mathrm{sec}$. without any change in the heart rate. This stimulation of ventricular tachycardia was due to the drug-induced " bundle branch block" and disappeared within two hours.

Paroxysmal Auricular Tachycardia. There were nine patients with this arrhythmia. All were successfully restored to regular sinus rhythm by means of procaine amide. Conversion occurred in all cases when between 3 and $5 \mathrm{~g}$. of the drug had been taken. In four, the drug was withdrawn, the arrhythmia recurred and was again controlled by means of procaine amide. The arrhythmia in one of these patients had previously proved refractory to quinidine. There was only one instance of marked toxicity in this group.

Auricular Premature Contractions. In two of three subjects, auricular premature contractions were successfully abolished by the use of procaine amide, in dosages of $1 \mathrm{~g}$. every six hours.

Nodal Tachycardia. There were four patients with nodal tachycardia. All were readily returned to sinus rhythm with procaine amide, one after receiving $3 \mathrm{~g}$. of the drug, and the other two after $4 \mathrm{~g}$. each. No toxic effects were noted.

Others. One patient with heart block and ventricular premature systoles was observed. This patient, with complete heart block and the pacemaker for the ventricle in the A-V node or bundle, was treated with procaine amide because of the presence of ventricular extrasystoles which were thought to be of clinical significance. She was a 68-year-old woman with arteriosclerotic heart disease and congestive heart failure, and received $2 \mathrm{~g}$. of procaine amide by mouth within eight hours. A cardiogram then revealed more frequent ventricular extrasystoles, including bigeminy. A third gram of procaine amide was given. One hour later she suddenly expired. Necropsy revealed no immediate cardiac cause of death.

\section{Maintenance}

Maintenance with procaine amide is an important problem and requires further study. The number of patients in this series with adequate follow-up, after conversion to sinus rhythm, were insufficient to permit more definite conclusions. In the majority, after conversion, a maintenance dose of $0.5 \mathrm{~g}$. every six hours was instituted and continued for two to four weeks. Following gradual withdrawal of the drug at that time, sinus rhythm was maintained.

In six patients requiring continuous maintenance over prolonged periods of time (one month or longer), we have noted a sensitivity to the dosage level of the drug. In one, as little as a 10 per cent reduction in dosage per day resulted in recurrence of the arrhythmia with restoration of sinus rhythm when larger doses were given. Two of these patients gradually developed tolerance to the drug. The increasing dosage level necessary for control of the arrhythmia finally could not be secured without undesirable side effects. Both of these had previously demonstrated similar behaviour with quinidine.

\section{Discussion}

The above data indicate that procaine amide, taken by mouth, may have an important effect upon arrhythmias of supraventricular origin (Garlett et al., 1951; Bernstein et al., 1951; and Schoffer et al., 1951). A substantial number of these arrhythmias may be converted to regular sinus rhythm. Several factors have been considered in respect to the influence of procaine amide upon these arrhythmias.

Arrhythmias of recent origin, as would be expected, responded most satisfactorily to the drug. However, 10 instances in which withdrawal of the drug resulted in recurrence of the arrhythmia with subsequent restoration of sinus rhythm when the drug was reintroduced, confirm us in the belief 
that in the great number of these patients procaine amide was responsible for the restoration of the normal rhythm.

Full digitalization had no significant effect upon the action of the drug. In several patients restoration of sinus rhythm was accomplished both before and after this.

The presence or absence of heart failure did not seem to influence the ability of procaine amide to abolish the arrhythmia. Three patients in frank congestive heart failure were returned to sinus rhythm with procaine amide. In two of these, the return to sinus rhythm was followed by disappearance of the congestive heart failure; the third required digitalization.

There were no cases of acute rheumatic fever in this series. Four of the patients with rheumatic heart disease were suspected of having low grade activity of the rheumatic process. In these patients, procaine amide had the following effect: the arrhythmia was abolished in one; auricular fibrillation was converted to auricular flutter in two; and in the fourth patient (J. G.), toxic effects were produced.

In this series there were arrhythmias that could not be abolished by the use of quinidine sulphate but responded well to procaine amide. The converse was also observed. In most subjects both drugs exhibited similar effects; i.e. regular sinus rhythm was re-established, auricular fibrillation was converted to auricular flutter, or no effect upon the arrhythmia was produced (Schoffer et al., 1951).

Toxic effects included changes in the cardiogram. These may be most simply described by stating that all complexes of the cardiogram may show distortion under the influence of procaine amide (a more complete report on these findings is in preparation).

Toxic symptoms included epigastric distress, nausea, vomiting, choking sensations, severe malaise, marked diaphoresis, and prostration. Hypotension, which occurs frequently with intravenous administration of the drug, was not observed. However; during the period when large doses were administered, the patients were kept in bed. Therefore, possible postural effects were not observed.

There were eight patients who exhibited the above complaints to a pronounced degree. Less severe symptoms were often present. It should be noted that restoration of sinus rhythm was accomplished in only one patient by continuing procaine amide beyond the toxic effect.

There were two instance of accidents during the course of treatment. One patient sustained a cerebral embolism after auricular fibrillation was converted to regular sinus rhythm. This was the only instance of cerebral embolism in the 44 patients with auricular fibrillation and six with auricular flutter among whom there were over 30 conversions of rhythm. Anticoagulant drugs were not used. The second with auricular flutter and multiple pulmonary infarctions was receiving the drug when he suddenly expired. No statement could be made as to the cardiac rhythm just before death. Another pulmonary embolus may have occurred. Necropsy was not done.

In regard to the patient with complete heart block, we believe that procaine amide should not have been used even though extrasystoles were present. Usurpation, not escape, is the indication for the drug. The A-V node appears to be quite sensitive (Kayden et al., 1951). It is possible that the node was more readily suppressed than the ectopic ventricular foci. Thus, when the A-V node is performing a vital function, such as emergency pacemaker for the heart, procaine amide should not be used.

A most interesting observation was recently reported in which the auricular arrhythmia proved to be more sensitive to procaine amide than the associated ventricular arrhythmia (Berstein et al., 1951). In two patients reported, with simultaneous dissociated paroxysmal tachycardia after intravenous procaine amide, the auricular disorder was converted to a sinus rhythm without the conversion of the ventricular.

Tachycardias of auricular and nodal origin, as well as ventricular tachycardia, are indications for the use of procaine amide. Auricular premature contractions and auricular fibrillation of recent origin respond well. Chronic auricular fibrillation or auricular flutter are difficult to abolish with procaine amide, responding in about 25 per cent of the cases. 


\section{SummaRY AND CoNCluSIONS}

Observations upon one hundred instances of arrhythmia or tachycardia of supraventricular origin occurring in 83 subjects are reported. Arrhythmias included auricular premature contractions, auricular and nodal tachycardia, auricular fibrillation and flutter. The restoration of regular sinus rhythm through the use of orally administered procaine amide has been accomplished in a significant proportion.

The type and duration of heart disease, the presence of congestive heart failure, and the influence of digitalis have all been shown to have little significant effect upon the response of the arrhythmia to procaine amide.

The type and duration of the arrhythmia is felt to be of the greatest importance in influencing the response to procaine amide. Auricular fibrillation and auricular flutter of over three years duration were resistant to the action of procaine amide while nodal rhythms were quite sensitive.

Some auricular arrhythmias that were refractory to quinidine were abolished by procaine amide. The converse was also observed.

Toxic effects of procaine amide noted in this series have included nausea, vomiting, malaise, weakness, marked diaphoresis, and profound prostration. Hypotension has not been noted. Cardiographic changes have been recorded.

It is concluded that orally administered procaine amide is of value in the control of arrhythmias and tachycardias of supraventricular origin.

We wish to express or appreciation to the members of the medical staff of the Beth Israel Hospital for their kind co-operation which made this study possible.

\section{REFERENCES}

Bernstein, L. M., Pascale, L. R., Littman, A., and Foley, E. F. (1951). Proceedings 24th Annual Meeting of American Heart Association, p. 37, Atlantic City.

Garlett, E. L., Berry, K., and Bellet, S. (1951). Amer. Fed. Clin. Res., Atlantic City.

Joseph, S. I., Helrich, M., Kayden, H. J., Orkin, L. R., and Rovenstein, E. A. (1951). Surg. Gyn. and Obs., $93,75$.

Kayden, H. J., Steele, J. M., Mark, L. C., and Brodie, B. B. (1951). Circulation, 4, 13.

Kay, H. B. (1948). Brit. Heart J., 10, 177.

Kinsman, J. M., Clay, H. L., Coe, W. S., and Best, M. M. (1951). Proc. Assoc. Amer. Physicians. Atlantic City.

Langendorf, R. (1948). Acta Cardiol., Supplement III, 13.

Mark, L. C., Berlin, I., Kayden, H. J., Rovenstine, E. A., Steele, J. A., and Brodie, B. B. (1950). J. Pharmacol. Exper. Therap., 98, 21.

Miller, H., Nathanson, M. H., and Griffith, G. C. (1951). J. Amer. med. Assoc., 146, 1004.

Schoffer, A. I., Blumenfeld, S., Pitman, R., and Dix, J. H. (1951). Amer. Heart J., 42, 115.

Stearns, N. S., and Callahan, E. J. (1951). Program 43rd Annual Meeting Amer. Soc. Clin. Invest., p. 55, April.

Vesell, H., and Kraemer, L. B. (1951). Amer. Heart J., 41, 280. 